\title{
A radar-based rainfall climatology of Great Britain and Ireland
}

\section{Article}

Published Version

Creative Commons: Attribution 3.0 (CC-BY)

Open Access

Fairman, J. G., Schultz, D. M., Kirshbaum, D. J., Gray, S. L. and Barrett, A. I. (2015) A radar-based rainfall climatology of Great Britain and Ireland. Weather, 70 (5). pp. 153-158. ISSN 1477-8696 doi: https://doi.org/10.1002/wea.2486 Available at https://centaur.reading.ac.uk/40319/

It is advisable to refer to the publisher's version if you intend to cite from the work. See Guidance on citing.

Published version at: http://dx.doi.org/10.1002/wea.2486

To link to this article DOI: http://dx.doi.org/10.1002/wea.2486

Publisher: Wiley

All outputs in CentAUR are protected by Intellectual Property Rights law, including copyright law. Copyright and IPR is retained by the creators or other copyright holders. Terms and conditions for use of this material are defined in the End User Agreement.

\section{www.reading.ac.uk/centaur}

\section{CentAUR}

Central Archive at the University of Reading

Reading's research outputs online 


\section{A radar-based rainfall climatology of Great Britain and Ireland}

\author{
Jonathan G. Fairman Jr, ${ }^{1}$ \\ David M. Schultz, ${ }^{1}$ \\ Daniel J. Kirshbaum, ${ }^{2}$ \\ Suzanne L. Gray ${ }^{3}$ \\ and Andrew I. Barrett ${ }^{3}$ \\ 'Centre for Atmospheric Science, \\ School of Earth, Atmospheric and \\ Environmental Sciences, The University \\ of Manchester \\ ${ }^{2}$ Department of Atmospheric and \\ Oceanic Sciences, McGill University, \\ Montreal, Canada \\ ${ }^{3}$ Department of Meteorology, University \\ of Reading
}

\section{Introduction}

The Met Office $1 \mathrm{~km}$ radar precipitation composite identifies the real-time precipitation rate across Great Britain and Ireland. It is produced by the Met Office by taking radar reflectivity from 18 radar sites, deriving the precipitation rate, and compositing to a fixed grid. This composite provides real-time guidance on weather conditions in an easyto-understand graphical format. The value to the public also extends to severe weather, as small-scale storm formation can be remotely monitored and extreme precipitation can be tracked. The Great Britain and Ireland radar composite includes data from 18 radar sites, 15 in the United Kingdom (operated by the Met Office), two in the Republic of Ireland (operated by Met Éireann) and one on the island of Jersey.

Most studies using the precipitation composite have used it in one of two ways: focusing on short time-scales, generally in the order of hours to days (e.g. Warren et al., 2014), or as the base dataset for manual determination of features that influence precipitation, such as tropopause folds (Antonescu et al., 2013) and cool-season convective lines (Clark, 2013). The precipitation composite has been used for creating precipitation total maps over time spans of a few hours (e.g. figure 5 of Warren et al., 2014) and driving hydrological models for localised extreme hydrological events (e.g. Biggs and Atkinson, 2011; Parkes et al., 2013), but less is known about how the radar precipitation composite performs over multi-annual scales. Some climatologies from radar-derived precipitation data have been created for the Himalayan region (Houze et al., 2007), USA (Carbone and Tuttle, 2008), The Netherlands (Overeem et al., 2009) and France (Tabary et al., 2012). Radar-based climatologies using space-based radar have also been performed (e.g. Nesbitt and Anders, 2009).

In this study, we examine the accuracy of a long-term precipitation climatology derived from the Great Britain and Ireland radar precipitation composite. To this end, we use 8 years (2006-2013) of radar composite data to compute annual-average precipitation totals and compare these to annual-average precipitation totals from gauge observations over the whole of Great Britain and Ireland. A secondary outcome of this work is to provide insights into any long-term biases of the radar measurements themselves.

\section{Data and methods}

The dataset used in this study is the Met Office radar-derived precipitation composite (Met Office, 2009), which since 2006 has been generated with a grid spacing of $1 \mathrm{~km}$. This product is derived from the Great Britain and Ireland radar network (Figure 1; Kitchen and Illingworth, 2011) and since mid-2005 has been operating under the data processing chain described by Harrison et al. (2009). There have been some changes to the network over 2006-2013 that may affect our climatology. Specifically, the High Moorsley radar was added in 2008, the Corse Hill radar was replaced by two radars at Holehead in 2007 and at Munduff Hill in 2008, and the Thurnham in Kent radar was introduced in 2006 (though it was not operational for much of the period of study). Despite these sources of uncertainty, the gridded and high-resolution data provided by the composite has the potential to significantly advance the understanding of Great Britain and Ireland precipitation.

Several steps are required to produce the radar-derived precipitation composite from the radar reflectivity $(Z)$, which is the returned signal of active pulses of $C$-band $(5.6 \mathrm{~cm}$ wavelength) radio waves. There is an adjustment for the variation in the vertical profile of reflectivity, to produce an estimate of the reflectivity at the Earth's surface (Kitchen et al., 1994; Smyth and Illingworth, 1998). This radar reflectivity is converted into precipitation rate $(R)$ by a constant $Z-R$ power law relationship of $Z=200 R^{1.6}$ (Marshall and Palmer, 1948; Marshall et al., 1955). This retrieval does not take into account variations in the microphysical species of the precipitation (e.g. graupel, snow, or hail) as it assumes that all precipitation is liquid. However, use of a microphysical species-based $Z-R$ relationship may only reduce the error in the precipitation rate retrieval by $10 \%$ (Koistinen et al., 2004). The retrieved precipitation rate is then corrected for orographic enhancement (Georgiou et al., 2011) and adjusted to match local gauge observations on a radar-by-radar basis (Kitchen et al., 1994; Lewis and Harrison, 2007; Harrison et al., 2012). These single-radar rain-rate retrievals are then composited to a uniform grid, weighting by both distance to the radar and pixel quality (Harrison et al., 2009; 2012). An overview of the process of precipitation retrieval from radar reflectivities over Great

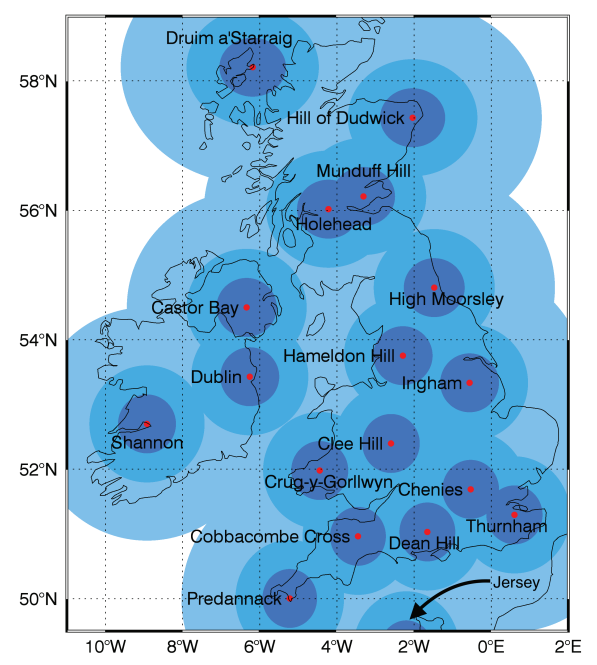

Figure 1. Locations of radar sites for the Met Office $1 \mathrm{~km}$ radar-derived precipitation composite. The filled circles indicate distances of 50,100 , and $200 \mathrm{~km}$ from the individual radars. [Correction added 19 May 2015 after original online publication: due to a publisher error, an incorrect version of Figure 1 was used. The corrected figure now appears above.] 
Britain and Ireland is given in Antonescu et al. (2013) and Liguori and Rico-Ramirez (2014).

The precipitation composite (an example of which at 1200 UTC on 9 July 2012 is shown in Figure 2) is available through the British Atmospheric Data Centre at $1 \mathrm{~km}$ grid spacing on a $1725 \times 2175$ grid every 5 min from the middle of 2005 through to the current day. There are several days of missing data throughout, although availability of data is greater than $90 \%$ in most months.

The annually averaged precipitation totals and precipitation frequency were both calculated from the precipitation composite. The annually averaged precipitation totals were calculated in two ways to show the impact on how missing data within the dataset changes the annual totals. First, the annual-averaged precipitation was calculated by adding composite data at $15 \mathrm{~min}$ intervals from January 2006 through December 2013, while treating missing data as 'no precipitation' and normalising to an average year. Second, the annualaverage precipitation was divided by the number of valid observations to determine the average observation (in $\mathrm{mmh}^{-1}$ ) over that period, and then multiplied by the number of hours in a year. This treats missing data as 'no observation' and interpolates the average observation over any missing time periods. Although most of the radars use 5 min scan intervals, the $15 \mathrm{~min}$ interval was chosen because data were available only from the Dublin and Shannon radars in Ireland (owned and operated by Met Éireann) at 15 min intervals. Precipitation frequency from the composite was computed by thresholding the precipitation composite at $5 \mathrm{~min}$ intervals into 'detected precipitation' at both $0 \mathrm{mmh}^{-1}$ and $1 \mathrm{mmh}^{-1}$ and determining the percentage frequency from the number of valid observations at each point; this approach takes into account the reduced frequency of radar data from Dublin and Shannon in the

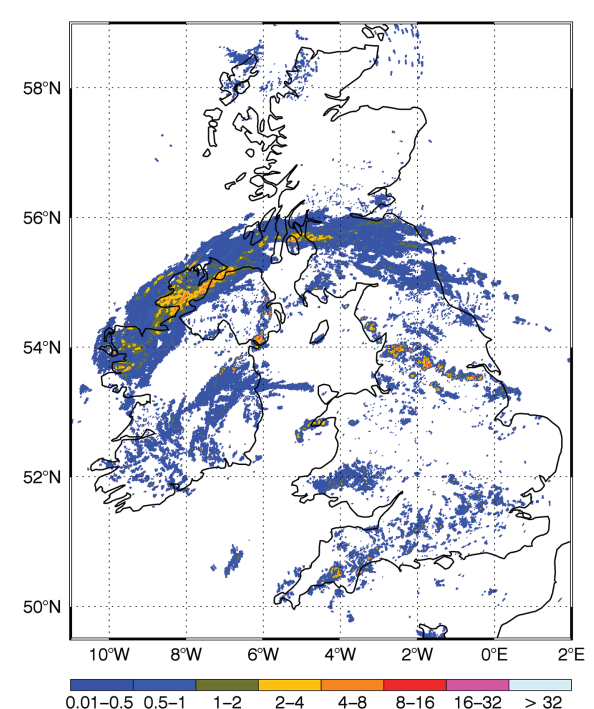

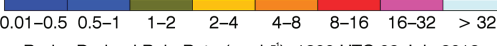

Radar-Derived Rain Rate $\left(\mathrm{mmh}^{-1}\right), 1200$ UTC 09 July 2012

Figure 2. Example of a radar-derived precipita154 tion composite: 1200 UTC on 9 July 2012. radar composite. This reduced frequency is at least in part due to the data reception cut-off of $5 \mathrm{~min}$ after validity time in order for data to be included in the Great Britain and Ireland composite.

To assess the accuracy of the radar-derived annually averaged precipitation totals, both hourly ( $0.2 \mathrm{~mm}$ tipping bucket) and daily (storage) precipitation gauge measurements from the Met Office Integrated Data Archive System (MIDAS) Land Surface Observation Stations Data of the British Atmospheric Data Centre archive were used to represent precipitation over the UK, whereas precipitation over the ROI was represented by the NOAA Integrated Surface Database (ISD; Smith et al., 2011), which is reported at $6 \mathrm{~h}$ intervals. Only quality-assured (QA) measurements (those with a MIDAS version level of 1 and final quality-controlled programs complete) from stations with observations in each month from 2006 to 2013 and with data available on $90 \%$ of the days in the study period were considered. The ISD data are quality checked before production so all observations present were used. As there are occasionally multiple observations per day at each site in the MIDAS daily precipitation data, strict date checking was used to prevent duplication. In the case that both observations were determined to be valid (both being listed as version 1), the more accurate QA code was used to determine the observation for that day.

These criteria led to 145 of 295 sites being selected from the hourly MIDAS observations, 1358 of 3932 sites being selected from the daily MIDAS observations, and 11 out of 23 sites from the Republic of Ireland ISD observations, for a total of 1514 sites. Missing observations were treated as a lack of data, so that the annual-average precipitation total was determined as the total recorded precipitation over 8 years divided by the number of valid observations, and then normalised to the number of expected observations during a year. This is to make sure the same method of computing the annual-average precipitation at the gauge sites is followed for both the gauge and radar composite data. Even though there are three observation intervals (hourly MIDAS data, daily MIDAS data and six-hourly ISD data), all of these sites are combined in the analysis after computing the annual-average precipitation for each location. Throughout the text when the differences between the gauge and radarderived precipitation totals are referred to, we refer to the single difference between the 8-year average precipitation and not the average difference from each year.

\section{Results}

Figure 3 shows the composite-derived mean annual precipitation over Great
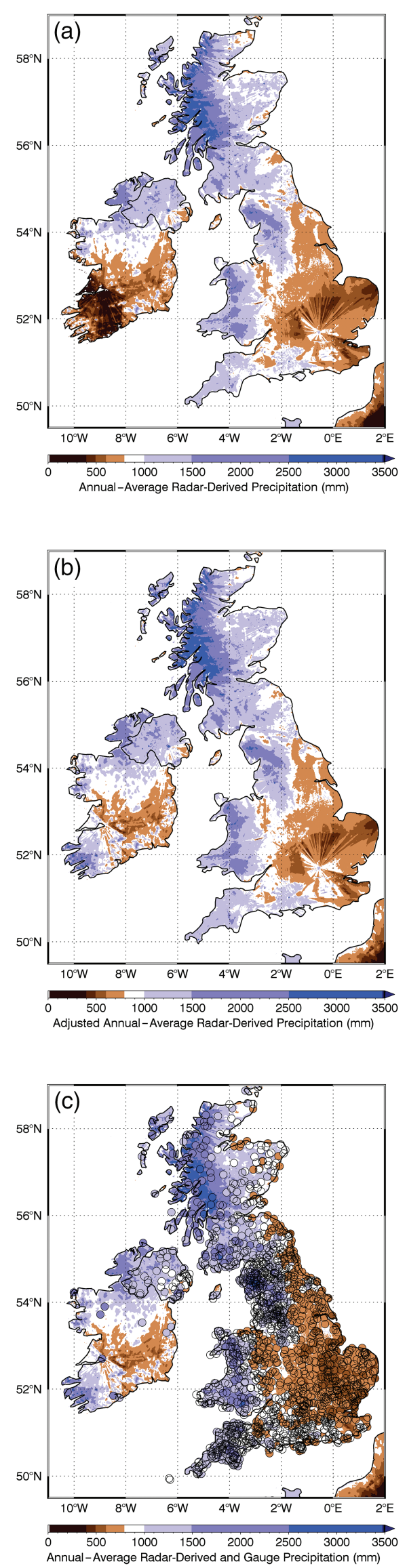

Figure 3. (a) Annual-average radar-derived precipitation from 2006 to 2013, considering missing data as no precipitation. (b) Annual-average radar-derived precipitation adjusted for missing data. (c) Adjusted radarderived precipitation with precipitation gauge measurements. 
Britain and Ireland for the 8 years 20062013 with missing data treated as no precipitation (Figure 3(a)); missing data treated as missing, with the annual-average precipitation representing the average observation extrapolated for 1 year of time (Figure 3(b)); the adjusted annual mean with the mean annual total from hourly precipitation gauges (filled circles in Figure $3(c)$ ). The wettest area in the UK is the western coast of the Scottish Highlands where the radar-derived precipitation total can exceed $6000 \mathrm{mmyr}^{-1}$. Other areas of high precipitation include the Lake District into the Pennines, the Welsh uplands and the northwestern coast of Ireland. There are several persistent biases in the yearly total. Natural and man-made obstacles lead to beam blocking at the Hameldon Hill (near Manchester) and Chenies (near London) radar locations. Consistent beam blocking also results in anomalous returns from the Druim a'Starraig site near Stornoway on the Isle of Lewis and at Castor Bay, near Belfast (Northern Ireland). The large variability around London is most likely not physical, particularly a linear feature near Chenies located around $52.3^{\circ} \mathrm{N}$, where the beam blocking disappears as the Ingham radar becomes the closest site. There are also several radial spokes around the Chenies radar. These features are most likely caused by differences in the calibration of the rain rate in the domain of a specific radar to specific ground-based locations, as well as the enhanced beam blocking at Chenies due to trees, telecom masts and electrical pylons surrounding the radar. There is little difference in the patterns of precipitation in the radar composite over the UK by the two differing treatments of missing data.

Precipitation totals in the south of Ireland are much more problematic than in the UK. A sharp gradient in total precipitation exists across Ireland, with areas nearest to Shannon Airport showing annual-average precipitation $400 \mathrm{~mm}$ lower than areas near Dublin in the unadjusted precipitation (Figure 3(a)) compared with the adjusted data, due to intermittency in the Shannon radar (Figure $3(b))$. However, there is still a large gradient in precipitation towards the southeastern parts of Ireland that corresponds with a lack of gauge information (Figure 3(c)). Areas covered by the Dublin radar have the lowest amount of precipitation in the adjusted radar-derived precipitation, however, there is a clear gradient that occurs between the domains of the Dublin, Shannon and Castor Bay radar locations. For the remainder of this study the adjusted radar-derived precipitation (Figure 3(b)) is used as a reference for the gauge precipitation, because of the reduced data frequency from the Shannon radar location leading to low rainfall totals in the unadjusted annual-average precipitation from the radar composite. This reduced data frequency is most likely due more to the $5 \mathrm{~min}$ cut-off time imposed rather than intermittency of the radar operating.

The adjusted radar-composite annualaverage precipitation for 2006-2013 is an average of $23.4 \mathrm{mmyr}^{-1}$ higher than the gauge annual-average precipitation from the hourly MIDAS and ISD land-surface stations (cf. Figures 4 and 5). However, there is significant variability in the radar and gauge differences between stations, leading to a standard deviation of $233 \mathrm{mmyr}^{-1}$, or about $23 \%$ of the average gauge annual-precipitation mean $\left(1016 \mathrm{mmyr}^{-1}\right)$. On average over the UK, the radar composite overestimates the annual-average precipitation by $29 \mathrm{mmyr}^{-1}$, around $3 \%$ of the annual-average precipitation gauge total. The mean error of the 11 sites across the Republic of Ireland is an underestimation of $781 \mathrm{mmyr}^{-1}$, or $46 \%$ of the annual-mean precipitation total of $1697 \mathrm{mmyr}^{-1}$. If we vary the number of sites in the analysis by varying the minimum number of days that a valid observation occurs, the mean error over the UK varies by a few millimetres: ranging from an overestimation of $26.9 \mathrm{mmyr}^{-1}$ (2.6\%) with requiring observations on $75 \%$ of the days to an overestimation of $21 \mathrm{mmyr}^{-1}$ (2.1\%) with requiring observations on $95 \%$ of the days. There is no change in the difference over the Republic of Ireland as the ISD dataset reports on every day in the analysis period.

Most of the values of the radar and gauge differences (Figure 4(a)) fall within $500 \mathrm{mmyr}^{-1}$, with the radar-derived composite overestimating precipitation at nine locations by over $500 \mathrm{mmyr}^{-1}$ (mostly near the west coast of Scotland) and underestimating at 37 sites by over $500 \mathrm{mmyr}^{-1}$, with the most common difference being a slight overestimation in the radar composite (Figure $4(b)$ ). The three sites of the highest overestimation (exceeding $600 \mathrm{mmyr}^{-1}$ ) are Badcaul and Glen Nevis in the Scottish Highlands, as well as Beragh Roscavey in Northern Ireland. The sites of consistent underestimation are generally located in Ayrshire, The Lake District, Wales, Cornwall and Ireland (Figure 5(a)). Over much of England and the east of Scotland, the radar composite slightly overestimates precipitation, possibly a result of the orographic precipitation enhancement.

The sites where the radar composite performs the best and the worst compared with gauge observations are shown in Figure 5(b). The location where the radar-derived precipitation differs from the gauges the least is Brackenber (Cumbria), where the annual mean precipitation difference is less than $1 \mathrm{~mm}$ from the annual-average precipitation of $985 \mathrm{mmyr}^{-1}$. The least accurate location is Beragh Roscavey in Northern Ireland, where the radar composite overestimates the gauge precipitation by $1652 \mathrm{mmyr}^{-1}$ (157\% of the annual-average gauge total
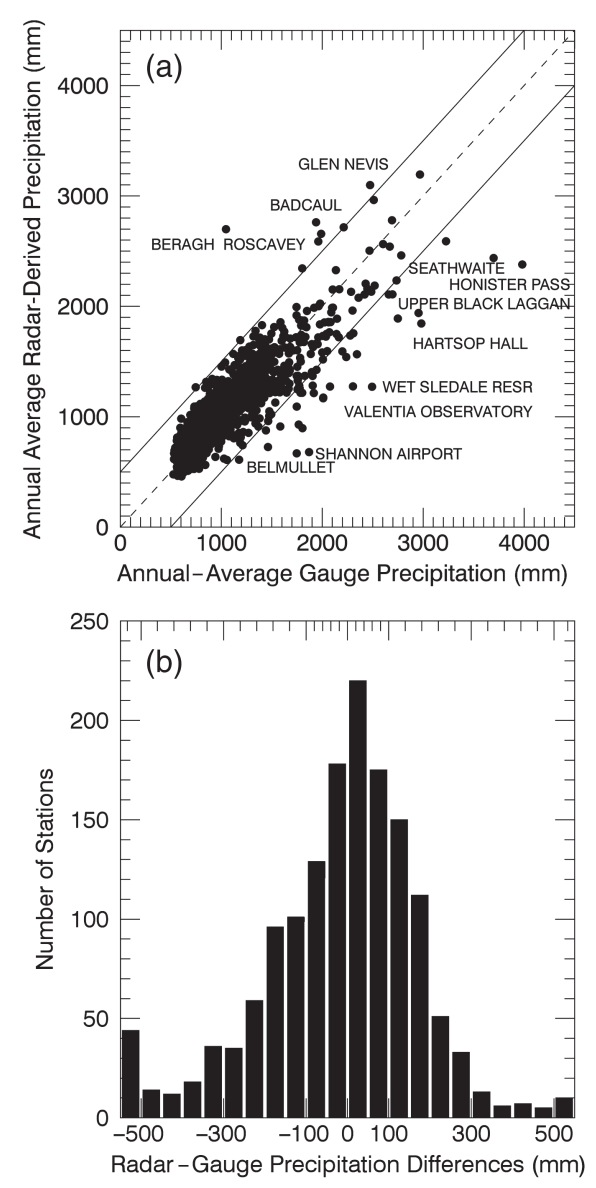

Figure 4. (a) Scatterplot of annual-average radar-derived precipitation and annual-average gauge precipitation for all precipitation gauges. The dashed line indicates $a$ one-to-one line and the solid black lines indicate $\pm 500 \mathrm{~mm}$ from the one-to-one line, with outlier values labelled. (b) Histogram of the radar-derived and gauge precipitation differences. All values greater than a $500 \mathrm{~mm}$ difference are grouped together.

of $1046 \mathrm{mmyr}^{-1}$ ). In Great Britain, the largest difference is present at Honister Pass (Cumbria), where there is a net underestimation of $1603 \mathrm{mmyr}^{-1}$ (40\% of the annualaverage gauge total of $\left.3981 \mathrm{mmyr}^{-1}\right)$. For the Republic of Ireland, the largest difference is an underestimation of precipitation of $1222 \mathrm{~mm}$ at the Valentia Observatory on the southwestern coast, which comprises $49 \%$ of the annual-average gauge precipitation. The smallest difference between the radar composite and precipitation gauges over the Republic of Ireland is $344 \mathrm{mmyr}^{-1}$, $28 \%$ of the annual-average gauge total, at Casement Aerodrome near Dublin.

As precipitation overestimation or underestimation in certain areas may influence the radar precipitation totals, the frequency of radar returns for varying thresholds has been examined to determine whether any biases exist. The map of precipitation frequency (radar precipitation-rate exceeding $0 \mathrm{mmh}^{-1}$, Figure 6(a)) has numerous areas with radar artefacts, making areas of frequent precipitation difficult to distinguish. These artefacts include the range rings 


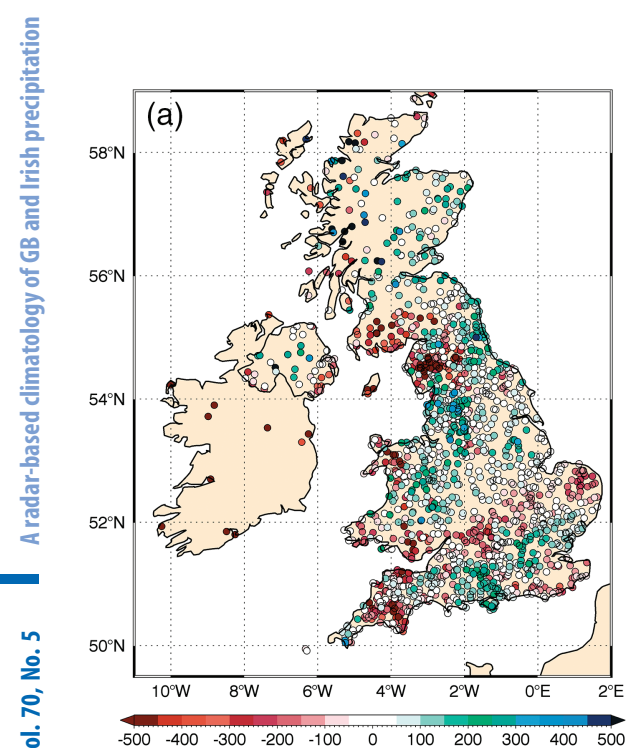

$\begin{array}{lllllllllll}-500 & -400 & -300 & -200 & -100 & 0 & 100 & 200 & 300 & 400 & 500\end{array}$ Radar-Gauge Precipitation Differences (mm)

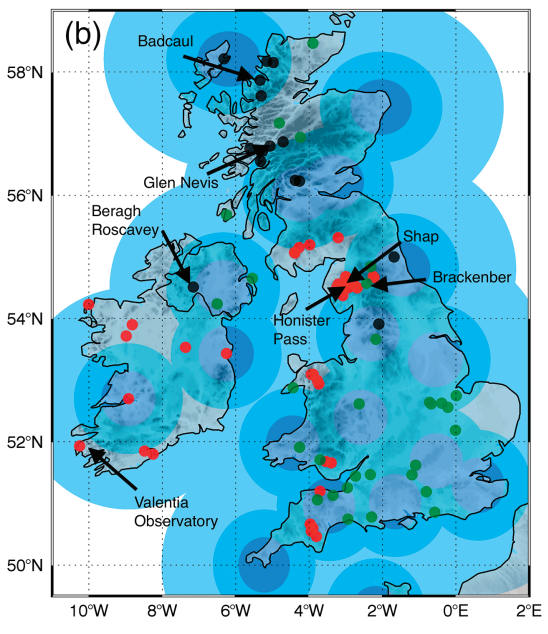

Figure 5. (a) Comparison between the precipitation from the radar composite and the gauges. (b) Extrema of the radar-gauge differences from (a). Black indicates overestimation by at least $500 \mathrm{mmyr}^{-1}$, red indicates underestimation by at least $500 \mathrm{mmyr}^{-1}$, and green indicates accuracy within $5 \mathrm{mmyr}^{-1}$. Also shown are the background orography (where dark shading is high orography) and radar range rings. The range rings indicate distances 50, 100 and $200 \mathrm{~km}$ from the radar locations, as in Figure 1.

caused by masking sea clutter in the lowest radar scan around the Druim a'Starraig radar site near Stornoway $\left(58^{\circ} \mathrm{N}, 6^{\circ} \mathrm{W}\right)$, as well as the anomalous returns off the coast of Scotland near the hill on which the Dudwick radar is sited $\left(57.5^{\circ} \mathrm{N}, 2^{\circ} \mathrm{W}\right)$. The frequency of radar precipitation-rate exceeding $0 \mathrm{mmh}^{-1}$ is less well correlated with gauge precipitation totals $(r=0.66)$ than the frequency of radar precipitation-rate exceeding $1 \mathrm{mmh}^{-1}$ $(r=0.88)$, as illustrated in Figure 6(a) and (b).The differences in these correlations indicates the presence of some spurious, weak non-precipitation echoes over land. However, these spurious echoes are uncorrelated with differences in cumulative precipitation between the composite and gauge measurements (not shown), indicating that
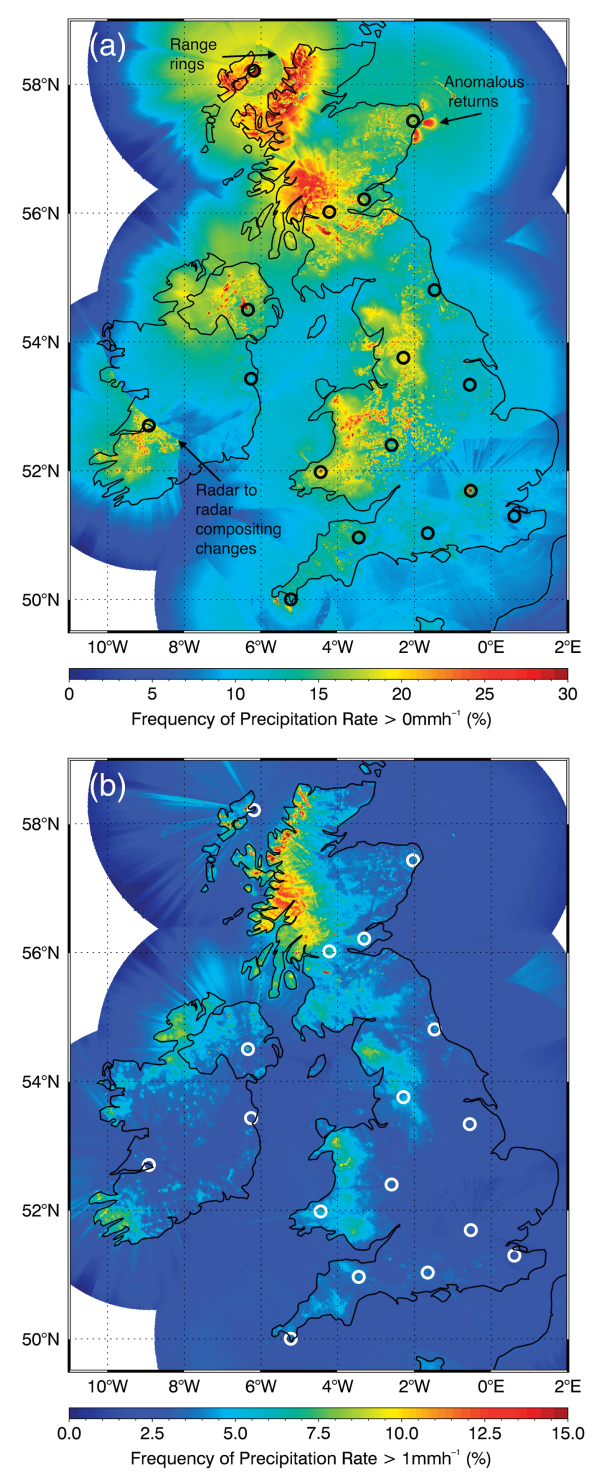

Figure 6. Frequency of precipitation rates exceeding (a) $0 m m^{-1}$ and (b) $1 m m h^{-1}$. Black (a) and white (b) rings indicate radar sites.

radar composite contribute little to errors in the composite precipitation total.

As the distance increases from the radar site, the radar beam will sample the

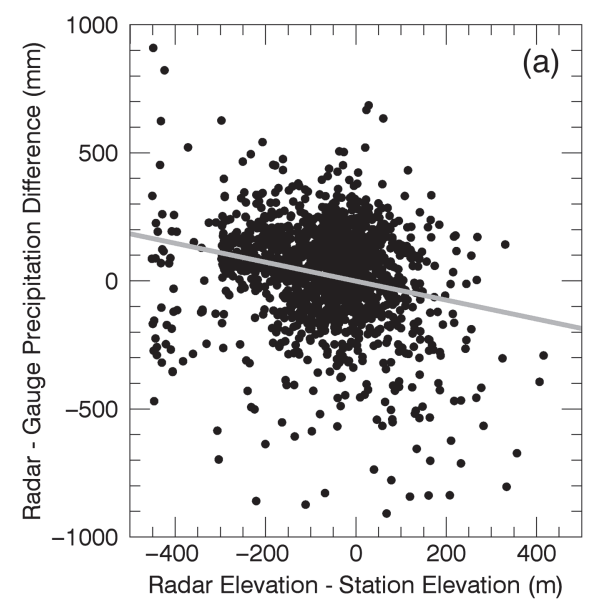

Figure 7. Radar-derived and gauge precipitation differences $(\mathrm{mm})$ compared with (a) the difference between radar elevation and station elevation $(\mathrm{m})$ and $(b)$ the distance to the nearest radar $(\mathrm{km})$.

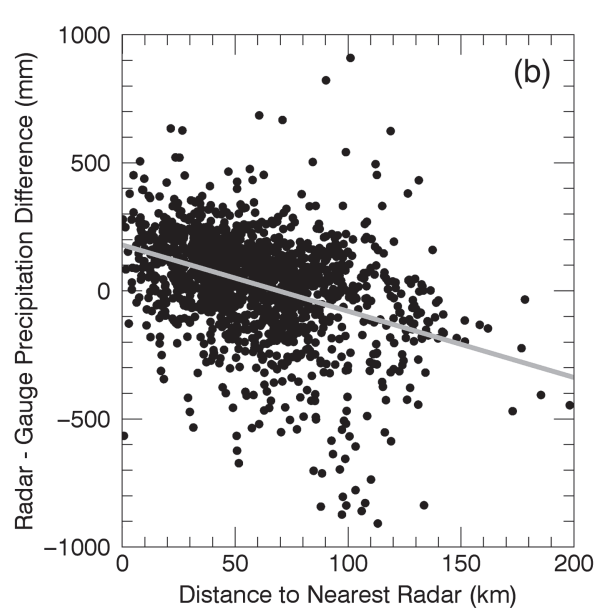

precipitation at increasing elevations above the ground, which could cause a systematic bias in the radar data for those pixels farther away from the radar location. Also, the beam height may exceed the height at which low-level precipitation is formed, especially precipitation enhanced by the seeder-feeder effect (e.g. Rutledge and Hobbs, 1983; Choularton and Perry, 1986). Although there are corrections that have been specifically made within the radar product to address these (e.g. Georgiou et al., 2011), the results may illustrate limitations in the accuracy of the orographiccorrection methodology. The differences in radar and station elevation, as well as the distance from the station to the radar, may shed light on the reasons for these consistent sources of error. However, the radar-gauge precipitation difference is only weakly correlated with radar-gauge elevation difference (Figure $7(a) ; r=-0.18$ ) and distance to the radar (Figure $7(b)$; $r=-0.373)$. This is also the case if the radargauge precipitation-difference percentage of the precipitation total is taken into account (not shown). This indicates that these two factors are not the only causes of error in the radar product, although they do contribute to the error.

The results of this study are consistent with prior comparisons between the UK radar-derived precipitation composite and gauge measurements (Biggs and Atkinson, 2011; Harrison et al., 2012; Parkes et al., 2013). However, most prior comparisons considered high-impact precipitation events, whereas this study considers all times with or without precipitation. Naturally, the radar composite will have higher average errors during high impact events than over longer periods of time, due to the high accuracy of the radar product when little or no rain occurs.

For this analysis, gauge-precipitation information is being considered as truth, however, there can be significant variations within the gauge observations due to 
environmental errors (such as wind speed) (e.g. Habib et al., 1999), random errors (e.g. Ciach, 2002) or sampling errors (e.g. Habib et al., 2001). These errors can be exacerbated in areas of strong wind speeds, as well as during times of intense rainfall. The environmental errors may contribute to the radar composite overestimation of precipitation compared with the gauge observations at the locations near the west coast of Scotland, however, the sites are from the MIDAS daily observations where windspeed information is unavailable.

\section{Conclusions}

The $1 \mathrm{~km}$ UK radar-derived precipitation composite has been examined over an 8-year period (2006-2013) by computing precipitation totals and frequency, and comparing these to surface precipitation observations from the MIDAS and ISD land-surface station network. The goal of the study was to determine the ability of the $1 \mathrm{~km}$ radar-derived precipitation composite to describe the distribution of rain across Great Britain and Ireland on a multiyear basis. This goal is important because the radar-derived precipitation data have greater spatial and temporal resolution compared with precipitation gauges.

The radar-derived precipitation composite provides a useful depiction of the annual distribution of precipitation, despite some radar data artefacts. This conclusion is perhaps not surprising given that the gauge data are incorporated in the radar precipitation estimation. On average, the radar precipitation-composite overestimates gauge precipitation by $23.4 \mathrm{mmyr}^{-1}$ (2\%) over the course of a year compared with surface precipitation gauges, with an average overestimation of $29 \mathrm{mmyr}^{-1}$ (3\%) over the UK and an average underestimation of $781 \mathrm{mmyr}^{-1}$ (46\%) over the Republic of Ireland. Several sites exhibit consistent annual underestimates or overestimates, with the worst underestimations typically found in areas of high elevation, far away from the radar, or both. Radar-beam blocking and overshooting may cause the largest differences between the radar-derived precipitation composite and surface-gauge readings. An example of a station that suffers from both beam blocking and overshooting is Shap in Cumbria, which has the worst performance from the hourly MIDAS network. There are also several local-scale changes in rainfall distribution that are occurring as well, as Brackenber in Cumbria (which is only $20 \mathrm{~km}$ away from Shap in a small rain shadow) has the most accurate performance of the radar composite. Overall, however, the difference between the radar composite and gauge precipitation is only weakly correlated with the distance from radar locations and the difference in radar and station elevation. Radar-gauge differences are not correlated with the radar-detection frequency, even though the precipitation totals are highly correlated with the precipitation frequency. Therefore, two significant factors contributing to error in the radar composite may be the retrieval of precipitation from radar returns or the corrections applied for changes in orography.

Within the UK, the radar composite exhibits the least accuracy between the Hameldon Hill, High Moorsley, Castor Bay and Holehead radars. This area, on the northeastern side of the Lake District and coastal Ayrshire (between $54-55^{\circ} \mathrm{N}$ and $\left.3-5^{\circ} \mathrm{W}\right)$, is greatly underestimated by the radar product. The highest overestimations by the radar composite are on the west coast of Scotland, which could be due to underestimation of the gauge precipitation due to high winds, but also a result of overestimation of the low-level enhancement of precipitation due to orographic effects. However, the worst overall area in Great Britain and Ireland is the Republic of Ireland, where the intermittent and poor-quality radar observations present at Shannon and Dublin lead to massive underestimation of precipitation totals, to the point where the radar composite over long periods is so poor that it has little value climatologically, even when corrected for the lack of data.

As the UK radars undergo an upgrade to a dual-polarisation Doppler radar system (http://www.metoffice.gov.uk/water/ radarimprovements), the accuracy of the precipitation composite product should increase, and some of the problems and biases presented here may be mitigated. However, the effects of removal of individual radars from February 2013 through the planned completion of the upgrades in winter 2017 may cause inconsistencies within the radar precipitation composite and should be considered when using the data on a climatological time-scale.

\section{Acknowledgements}

This work was supported by the National Environmental Research Council (NERC) as part of the PRESTO (PREcipitation STructures over Orography) project (NE/1024984/1). We thank the Met Office and the British Atmospheric Data Centre for the $1 \mathrm{~km}$ radar precipitation composite and MIDAS precipitation-gauge data. We thank Bogdan Antonescu for many discussions about the radar composite and the two anonymous reviewers for their instructive comments that have improved the article. We acknowledge excellent feedback received from the radar group at the University of Reading. Comments from Kath Morris greatly improved the quality of this manuscript.

\section{References}

Antonescu B, Vaughan G, Schultz DM. 2013. A five-year radar-based climatology of tropopause folds and deep convection over Wales, United Kingdom. Mon. Weather Rev. 141: 1693-1707.

Biggs E, Atkinson PM. 2011. A comparison of gauge and radar precipitation data for simulating an extreme hydrological event in the Severn Uplands, UK. Hydrol. Processes 25: 795-810.

Carbone RE, Tuttle JD. 2008. Rainfall occurrence in the U.S. warm season: the diurnal cycle. J. Clim. 21: 4132-4146.

Choularton TW, Perry SJ. 1986. A model of the orographic enhancement of snowfall by the seeder-feeder mechanism. Q. J. R. Meteorol. Soc. 112: 335-345.

Ciach G. 2002. Local random errors in tipping-bucket rain gauge measurements. J. Atmos. Oceanic Technol. 20: 752-759.

Clark MR. 2013. A provisional climatology of cool-season convective lines in the UK. Atmos. Res. 123: 180-196.

Georgiou S, Gaussiat N, Lewis H. 2011. Analysis of a scheme to dynamically model the orographic enhancement of precipitation in the UK, in Weather Radar and Hydrology Proceedings of a Symposium held in Exeter, UK, Publication 351. IAHS: Wallingford, UK, pp 201-206.

Habib E, Krajewski WF, Nespor V et al. 1999. Numerical simulation studies of rain gage data correction due to wind effect. J. Geophys. Res. 104(D16): 19,723-19,733.

Habib E, Krajewski W, Kruger A. 2001 Sampling errors of tipping-bucket rain gauge measurements. J. Hydrol. Eng. 6 : 159-166.

Harrison DL, Scovell RW, Kitchen M. 2009. High-resolution precipitation estimates for hydrological uses. Proc. ICE Water Manage. 162(2): 125-135.

Harrison DL, Norman K, Pierce C et al. 2012. Radar products for hydrological applications in the UK. Proc. ICE - Water Manage. 165(WM2): 89-103.

Houze RA, Wilton DC, Smull BF. 2007 Monsoon convection in the Himalayan region as seen by the TRMM Precipitation Radar. Q. J. R. Meteorol. Soc. 133: 13891411.

Kitchen M, Illingworth A. 2011. From observations to forecasts - Part 13: The UK weather radar network - past, present and future. Weather 66: 291-297.

Kitchen M, Brown R, Davies AG. 1994

Real-time correction of weather radar data for the effects of bright band, range and orographic growth in widespread precipitation. Q. J. R. Meteorol. Soc. 120 : 1231-1254.

Koistinen J, Michelson DV, Hohti H et al. 2004. Operational measurement of precipitation in cold climates, in Weather Radar: Principles and Advanced Applications. Meischner $\mathrm{P}$ (ed.). Springer-Verlag: Berlin, pp 78-114.

Lewis HW, Harrison DL. 2007. Assessment of radar data quality in upland catchments. Meteorol. Appl. 14: 441-454.

Liguori S, Rico-Ramirez MA. 2014. A review of current approaches to radarbased quantitative precipitation forecasts. Int. J. River Basin Manage. 12: 391-402. 
Marshall JS, Palmer WKM. 1948. The distribution of raindrops with size. J. Meteorol. 5: 165-166.

Marshall JS, Hitschfeld W, Gunn KLS. 1955. Advances in radar weather. Adv. Geophys. 2: 1-56.

Met Office. 2009. Fact sheet number 15 : radar. National Meteorological Library and Archive. http://www.metoffice.gov.uk/ learning/library/publications/factsheets (accessed 15 December 2013).

Nesbitt SW, Anders AM. 2009. Very high resolution precipitation climatologies from the Tropical Rainfall Measuring Mission precipitation radar. Geophys. Res. Lett. 36: L15815.

Overeem A, Holleman I, Buishand A. 2009. Derivation of a 10 -year radar-based climatology of rainfall. J. Appl. Meteorol. Climatol. 48: 1448-1463.

Parkes BL, Wetterhall F, Pappenberger F et al. 2013. Assessment of a 1-hour gridded precipitation dataset to drive a hydrological model: a case study of the summer 2007 floods in the Upper Severn, UK. Hydrol. Res. 44(1): 89-105.

Rutledge SA, Hobbs PV. 1983. The mesoscale and microscale structure and organization of clouds and precipitation in midlatitude cyclones. VIII: a model for the 'Seeder-Feeder' process in warm frontal rainbands. J. Atmos. Sci. 40: 1185-1206

Smith A, Lott N, Vose R. 2011. The integrated surface database: recent developments and partnerships. Bull. Am. Meteorol. Soc. 92: 704-708.

Smyth TJ, Illingworth AJ. 1998. Radar estimates of rainfall rates at the ground in bright band and non-bright band events. Q. J. R. Meteorol. Soc. 124: 2417-2434.

Tabary P, Dupuy P, L'Henaff G et al. 2012. A 10-year (1997-2006) reanalysis of quantitative precipitation estimation over France: methodology and first results, in Weather Radar and Hydrology (Proceedings of a Symposium held in Exeter, UK, April 2011), Publication 351. IAHS: Wallingford, UK, pp 255-260.

Warren RA, Kirshbaum DJ, Plant RS et al. 2014. A 'Boscastle-type' quasistationary convective system over the UK Southwest peninsula. Q. J. R. Meteorol. Soc. 140: $240-257$.

Correspondence to: Jonathan G. Fairman Jr jonathan.fairman@manchester.ac.uk

(c) 2015 The Authors. Weather published by John Wiley \& Sons Ltd on behalf of Royal Meteorological Society.

This is an open access article under the terms of the Creative Commons Attribution License, which permits use, distribution and reproduction in any medium, provided the original work is properly cited.

doi:10.1002/wea.2486

\section{Atmospheric divergence over equatorial East Africa and its influence on distribution of rainfall}

\section{Kiprop Vincent Koech}

Department of Meteorology, University of Nairobi, Kenya

\section{Introduction}

In East Africa, rainfall amounts and distribution are the most important factors governing crop yields (Muti and Kibe, 2009). Since most food production systems over the region are mainly rain-fed, weather forecasts are crucial. Therefore, this analysis focuses on divergence of the atmospheric flow with the aim of contributing to the understanding of regional weather.

The idea that surface convergence and rainfall are related is not new. Marshall et al. (2001) found that initial rainfall morphology is related not only to the amount of low-level convergence but to the depth of the convergence. Convergence is the piling up of air above a region, whereas divergence is the spreading of air above some region (Ahrens, 2011). Convergence and divergence of air may result from changes in wind speed or convergence may be due to frictionally driven, cross-isobaric flow (Zehnder, 2001).

\section{Area of study}

The area under the focus of this analysis is equatorial East Africa (Figure 1). Twentyone stations have been selected to represent the region, based on homogeneous rainfall zones.

East Africa experiences two climatological rainy seasons. During southern hemisphere summer, the weather of equatorial East Africa is influenced by the northeast monsoon. During northern hemisphere summer, the region is under the influence of the southeast monsoon. The southeast monsoon is cool, moist and shallow, and is generally associated with cool, cloudy and dry conditions over the region (Christian et al., 2011).

\section{Data}

Two datasets were used in the analysis. These are monthly mean rainfall and divergence data for the period 1979-2008. The rainfall data were obtained from the National
Oceanic and Atmospheric Administration (NOAA) Climate Prediction Centre (CPC). The spatial resolution of the CPC dataset is $0.5^{\circ} \times 0.5^{\circ}$. Divergence data were obtained from European Centre for Medium Range Weather Forecasting (ECMWF) ERA-Interim dataset. The spatial resolution of the ECMWF dataset is $0.125^{\circ} \times 0.125^{\circ}$.

\section{Seasonal variation of upper tropospheric divergence}

As atmospheric sounding and instability indices reveal, most of the tropical zone is essentially convective, although variations occur on diurnal, latitudinal, and seasonal scales, as well as with altitude (Galvin, 2008). In this section, we focus on the seasonal variation of upper tropospheric divergence over the region. The seasonal variation is based on the monthly mean for the period 1979-2008.

The seasonal march of upper tropospheric divergence has a bimodal pattern (Figure 2). During March-April-May (MAM) and October-November-December (OND), there is peak upper level divergence at 300 and $200 \mathrm{hPa}$ over the region. During 